\title{
Coaching Collaboration in a Computer-Mediated Learning Environment
}

\author{
María de los Angeles Constantino- \\ González
}

Dept. of Computer Sciences

ITESM Campus Laguna

aconstan@campus.lag.itesm.mx

\author{
Daniel D. Suthers \\ Dept. of Information and Computer Sciences \\ University of Hawai' $i$ at Manoa \\ suthers@hawaii.edu
}

\begin{abstract}
We evaluated a pedagogical agent that coaches collaborative problem solving by tracking student participation and comparing students' individual and group solutions. The software coach encourages negotiation when differences are detected between solutions, and encourages participation in other ways. Evaluations based on expert judgment and on students' behavior shows that the quality of the advice was good and that the coach helped guide the collaborative session, although specific areas for improvement were identified.
\end{abstract}

\section{Keywords}

collaborative distance learning, intelligent agents, entity-relationship modeling, socio-cognitive conflict

\section{INTRODUCTION}

A communication channel by itself does not guarantee effective collaboration between distance learners. Participants should be guided to help students leverage the advantages of learning with others. Yet it is difficult for human facilitators to guide many teams working synchronously. Several systems have been designed to guide online synchronous collaboration (Jermann, Soller \& Muehlenbrock, 2001). Most of these systems use restricted menudriven or sentence-opener interfaces to track students' dialogue and give guidance based on dialogue models. Wanting an approach that would not excessively restrict natural language interaction and would not require extensive knowledge engineering for each domain, we investigated the potential of a basic ability to detect semantically interesting differences between two representations of problem solutions, coupled with simple tracking of individual's quantity of participation, feedback given, and discussion. A software coach was designed based on the Socio-Cognitive Conflict Theory and Cognitive Dissonance theories, and implemented as part of a computermediated environment in which students construct Entity-Relationship (ER) diagrams as solutions to database modeling problems. ER modeling was selected due to its collaborative nature and its use of easily compared representations. This paper reports on how students used and evaluated the coach's advice.

\section{COLER}

COLER (COllaborative Learning environment for Entity-Relationship modeling) is a web-based collaborative learning environment in which students can solve database-modeling problems. COLER is designed for sessions in which students first solve problems individually, and then work synchronously in small groups to develop group solutions. A personal coach gives advice based on conflicts between the contents of individual and group diagrams and on imbalances in students' participation. Several heuristic control strategies were specified to recognize relevant learning opportunities and to provide for the selection of appropriate advice. Details are provided in ConstantinoGonzález \& Suthers (2001) or Constantino-González et al. (2001).

\section{EVALUATION}

COLER's performance was judged by comparison to expert judgment, student impressions, and how students responded to the advice. Five sessions were conducted, each with a different team of three students who were taking or had taken a database course. A domain expert also participated. Participants were located in different rooms, each containing a computer with COLER installed and Internet access. Students worked on an ER modeling problem individually for about 30 minutes. Then they initiated the collaborative session. At the end of the two-hour session, students answered a questionnaire regarding COLER's performance. The papers cited above reported on evaluations of the quality and coverage of advice and of the role of various knowledge-sources in generating this advice. This paper focuses on how students used and evaluated the coach's advice.

COLER's advice was codified according to videotapes and chat transcripts. Advice was codified as Taken if the coached student performed the action suggested by COLER; Ignored if the coached student didn't follow the advice; 
Not Longer Needed when the situation changed just after the advice was given; and Not Evaluated when there was not enough information to empirically determine the advice status or when system failures occurred. The students took $40 \%$ of the total advice instances while $28 \%$ was ignored. Not Longer Needed advice represented $21 \%$ of the total advices, and $11 \%$ could not be evaluated. Overall, students took $59 \%$ of the evaluated advice that was still needed at the time it was given. The Expert categorized most of the advice taken by the students as "reasonable." Some ignored advice was evaluated as reasonable while others as "so-so." Most of the ignored reasonable advice suggested discussion of a difference without mentioning its specific type. So-so ignored advice was computed because of misspellings in names. Several Feedback and Continue Task advices, which are based on timeouts, were not longer needed since they were given just when conditions in the environment changed. This problem can be eliminated by re-checking conditions before giving the selected advice.

Advice rated by students as "useful" included pointing out differences between their solutions, encouraging them to share and discuss their ideas, to explain their reasoning, and to contribute to the group diagram, and suggesting that they verify their work when their contribution to the group was different from their own individual work. Advice was generally rated as useful only when students could do something in response. Almost all of the advice was given at appropriate times; however, some advice was given just after the action suggested was performed. Most of the students thought that the presence of a coach during the session helped guide and coordinate the collaborative session and establish the group dynamics required in collaborative learning. Most students said they reaffirmed their ER knowledge and learned about collaboration during the session. Some students suggested that more specific advice be given, and that additional types of messages be included, for example helping to solve the problem, indicating common mistakes in the diagram and giving feedback on how they are doing. Other students suggested that the coach compare individual solutions and then give suggestions related to what it finds different. Students also indicated that sometimes advice should be given to the whole group instead of just to individuals.

\section{CONCLUSIONS}

We found that reasonable advice could be generated based primarily on comparing students' individual and group solutions and on tracking student participation, although some refinements are needed to eliminate sensitivity to spelling errors and ensure that the advice is still applicable before it is given, and other knowledge sources will help increase the range of advice given. The approach should generalize to all domains in which students construct formal representations of problem solutions that can be compared for significant differences.

\section{ACKNOWLEDGMENTS}

Constantino-González was funded by ITESM Campus Laguna and by CONACYT, and Suthers was funded by the Presidential Technology Initiative and NSF's Learning and Intelligent Systems. We thank our many colleagues at ITSEM and the University of Pittsburgh for their collaboration and support.

\section{REFERENCES}

Constantino-González, M. A., Suthers, D. D. \& Icaza, J. (2001) Designing and Evaluating a Collaboration Coach: Knowledge and Reasoning. In Artificial Intelligence in Education (Proc. 10 ${ }^{\text {th }}$ AI-ED, May 19-23, San Antonio Texas), J. D. Moore, C. L. Redfield, \& W. L. Johnson (Eds.), Amsterdam: IOS Press, 2001, pp. 176-187.

Constantino-González, M. A., \& Suthers, D. D. (2001) Coaching Collaboration by Comparing Solutions and Tracking Participation. In P. Dillenbourg, A. Eurelings, K. Hakkarainen (Eds.) European Perspectives on Computer-Supported Collaborative Learning, Proc. First European Conference on CSCL, Universiteit Maastricht, Maastrict, the Netherlands, March 22-24 2001, pp. 173-180.

Jermann, P., Soller, A., \& Muehlenbrock, M. (2001). From Mirroring to Guiding: A Review of State of the Art Technology for Supporting Collaborative Learning. In P. Dillenbourg, A. Eurelings, K. Hakkarainen (Eds.) European Perspectives on Computer-Supported Collaborative Learning, Proc. First European Conference on CSCL, Universiteit Maastricht, Maastrict, the Netherlands, March 22-24 2001, pp. 324-331. 